\title{
Review Article \\ Regional Climate Modeling over South America: A Review
}

\author{
Silvina A. Solman \\ Centro de Investigaciones del Mar y la Atmósfera (CIMA/CONICET-UBA), DCAO/FCEN, UMI IFAECI/CNRS, \\ Ciudad Universitaria Pabellón II Piso 2, C1428EGA Buenos Aires, Argentina \\ Correspondence should be addressed to Silvina A. Solman; solman@cima.fcen.uba.ar
}

Received 12 April 2013; Revised 17 June 2013; Accepted 19 June 2013

Academic Editor: Vadlamudi B. Rao

Copyright (C) 2013 Silvina A. Solman. This is an open access article distributed under the Creative Commons Attribution License, which permits unrestricted use, distribution, and reproduction in any medium, provided the original work is properly cited.

This review summarizes the progress achieved on regional climate modeling activities over South America since the early efforts at the beginning of the 2000s until now. During the last 10 years, simulations with regional climate models (RCMs) have been performed for several purposes over the region. Early efforts were mainly focused on sensitivity studies to both physical mechanisms and technical aspects of RCMs. The last developments were focused mainly on providing high-resolution information on regional climate change. This paper describes the most outstanding contributions from the isolated efforts to the ongoing coordinated RCM activities in the framework of the CORDEX initiative, which represents a major endeavor to produce ensemble climate change projections at regional scales and allows exploring the associated range of uncertainties. The remaining challenges in modeling South American climate features are also discussed.

\section{Introduction}

One of the main motivations for developing Regional Climate Models (RCMs) has been the need for producing climate information at the regional level to assess the impacts of climate change. It is a well-known fact that, to date, Atmosphere Ocean Global climate Models (AOGCMs) are the only tools available to predict the future evolution of the climate system in response to anthropogenic forcings, such as the increase in greenhouse gas (GHG) concentrations. During the last decades, coupled global models have been continuously improved, mostly due to the increasing computational capacity and the improved representation of different components of the climate system: the atmosphere, the oceans, and the land-surface. However, the most updated global models within the suit of the CMIP5 initiative [1] operate on horizontal resolutions of the order of hundreds of kilometers [2].

The lack of regional details in current AOGCMs limits their capability in capturing regional-scale processes forced by topographic features or other regional-scale forcings. These regional-scale forcings are responsible for modulating the large-scale circulation features that determine the regional climate. Moreover, coarse resolution also limits the applicability of global model outputs for impact studies that demand information on much finer spatial scales. Since the early 1990s, RCMs became the most widespread methodology to add further detail to global climate simulations. After the pioneering work by Giorgi and Mearns [3], the development of RCMs has led to increased resolution, longer model simulations, and developments towards regional climate system models. During recent years, coordinated efforts for several regions of the world have started to emerge not only to further improve the quality of the RCM results but also to explore the associated uncertainty of the regional climate model products. The CORDEX initiative [4] is an excellent example of a coordinated effort all around the world which aims to further advance the state of the art in regional climate modeling and to provide valuable information for the impact community.

South American climate and its variability are affected by remote, regional, and local forcings. Owing to its considerable meridional extension and prominent topography, South America (SA) exhibits diverse patterns of weather and climate, including tropical, subtropical, and extratropical features. The most important feature of the regional geography is the complex Andes chain, which extends all along the western coast and is characterized by a narrow barrier channeling the flow in the central part of the continent (Figure 1). The Andes not only act as a climatic wall with 


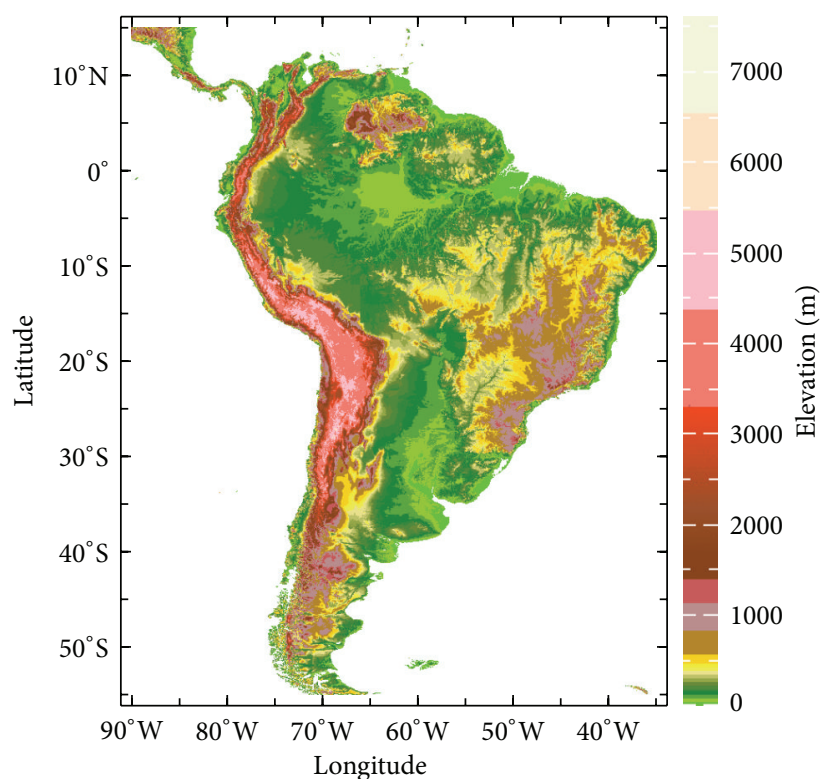

FIgURE 1: Topographic features of the South American continent. Source: NOAA NGDC GLOBE elevation dataset.

dry conditions to the west and moist conditions to the east at tropical/subtropical latitudes (the pattern reverses in midlatitudes) but also foster tropical-extratropical interactions, especially along their eastern side.

The seasonal migration of the inter tropical convergence zone (ITCZ) largely controls climate conditions over the northern part of the continent. During the austral summer season, the large-scale circulation at upper levels is characterized by a high-pressure center over the Altiplano, a trough extending from northeast Brazil towards the tropical Atlantic Ocean and westerly circulation over subtropical and higher latitudes. At low levels, the semipermanent subtropical highs over the Atlantic and Pacific Oceans dominate the large-scale features. Easterly flow from the Atlantic Ocean is channeled southwards by the Andes mountains into the Chaco low, which represents the main source of moisture over southern Brazil and the subtropical plains of southern SA. One of the major components of the continental warm season precipitation regime over tropical and subtropical latitudes is the South American monsoon system (SAMS) [5]. Over the southern part of the continent, synoptic activity is dominated by the presence of the Pacific storm track and its interaction with the Andes.

During winter season, the recurrent passages of cold fronts progressing north-eastward east of the Andes from subpolar latitudes and the upper level troughs propagating eastward at subtropical latitudes are the triggering factors for strong cyclogenesis over southeastern SA. The presence of the Pacific subtropical high, its seasonal meridional shift, and the sea surface temperature over the subtropical Pacific Ocean define the seasonal cycle of precipitation west of the Andes.

The variability of the South American climate from intraseasonal to interdecadal timescales results from the superposition of several large-scale phenomena: El NiñoSouthern Oscillation (ENSO), the control exerted by anomalous sea surface temperature (SST) over subtropical Atlantic and Pacific Oceans, SST anomalies over the tropical North Atlantic Ocean which affect climate variability over the Amazonia and Northeastern Brazil and high-latitude forcing, such as by the Antarctic Oscillation (AAO) and the North Atlantic Oscillation (NAO). A thorough review of the main characteristics of the South American climate and its variability can be found in Garreaud et al. [6] and references therein.

Owing to the variety of dynamical mechanisms controlling South American climate and its variability, modeling regional climate seems to be a challenging goal. Regional climate modeling efforts over the South American continent have been increasingly developed during the last decade. This paper presents an overview of the development of regional climate modeling activities over SA during the last 10 years, with the aim of highlighting the major achievements and pending challenges. Two outstanding initiatives led to an enormous progress in producing valuable information for impact assessment studies: the CLARIS-LPB Project [7] and CORDEX [4]. Progress in modeling the South American climate within these major coordinated initiatives is described in Section 3. Ongoing activities within the CORDEX-South America framework are presented together with the expected outcomes in Section 4. Outstanding questions associated with remaining challenges are reviewed in Section 5. This review is far from being complete, but the most relevant results leading to further improvements are mentioned. The references provided are not exhaustive, and the discussion regarding main achievements does not venture into deep detail.

\section{Early Efforts on Regional Climate Modeling over South America}

As stated in the introduction, the early developments in regional climate modeling were focused on simulating NorthAmerican climate during the early 1990s $[8,9]$. The pioneering studies using RCMs over SA focused mainly on monthly to seasonal-scale simulations. The first attempt exploring the dynamical downscaling technique over SA was carried out by Chou et al. [10] who performed a couple of 1-month long simulations with the aim of exploring the quality of extended range forecasts nesting the ETA RCM into the CPTEC/COLA GCM. Though the RCM was configured using a fairly low resolution $(80 \mathrm{~km})$, the authors discussed the added value of the RCM compared with the driving GCM, a topic that became of major relevance later on. Soon after, Menéndez et al. [11] developed a numerical nesting system to simulate wintertime climate of the eastern South Pacific-South America-western South Atlantic region, using a limited area model (the Limited Area Hibu Model-LAHM) driven by the LMDZ GCM. Their study aimed at exploring the capability of the nesting system in reproducing mean climate conditions and, hence, it is the very first attempt in exploring the capability of a RCM in capturing the main climatic features of the observed climate. 
Due to computational constraints, they simulated 6 separated July months and evaluated the RCM climatology compared with the driving GCM, reanalysis, and gridded datasets for precipitation and temperature. Their model configuration was set using $100 \mathrm{~km}$ resolution for the RCM and close to $5^{\circ}$ for the driving GCM. Though the authors found that the RCM generally improved the representation of the observed climate features compared with the driving GCM, this was not true for the 2-meter temperature. A very simplified landsurface scheme used in the regional model (a bucket model) and the low resolution of the RCM may be the reason for this unexpected model performance. A similar study was performed by Nicolini et al. [12] who simulated ten separate 30-day simulations for both January and July, nesting the CSIRO division of atmospheric research limited area model (DARLAM) into the CSIRO GCM. Both the global and regional models used the same set of physical parameterizations and the same number of vertical levels; hence, the study focused on evaluating the impact of increasing the horizontal resolution (from $500 \mathrm{~km}$ to $125 \mathrm{~km}$ in the global and regional models, resp.) on the capability of the nesting system during July and January, representatives of winter and summer seasons, respectively. The authors found that the RCMs were able to reproduce the observed climate better than the driving GCM, reaching better performance for July, particularly for near-surface variables. However, the use of the same physical parameterizations in both models could lead to physical inconsistencies in the RCM.

Though these very first efforts led to encouraging results, the regional model domains covered only the southern part of the South American continent and they were limited due to computational constraints in terms of both resolution and length of the simulations. The major shortcoming of these studies relied on the fact that the RCM simulations were not continuous but individual 1-month simulations were gathered to produce the corresponding climatologies. Moreover, in these studies, the land-surface representation were based on very simple schemes and no spin-up time was taken into account, which may explain the limited improvements achieved in the RCM results.

Nobre et al. [13] and Misra et al. [14, 15] performed several seasonal-scale simulations that focused mainly on the northern part of SA with the aim of evaluating the capability of a nesting modeling system to reproduce the interannual variability signal associated with ENSO. Precipitation and circulation features for extreme ENSO events (La Niña and El Niño) were simulated in order to explore the predictive capability of the RCMs. These studies represented an important progress in dynamical downscaling over the region due to several reasons. First, they included several realizations of the driving GCM in order to build ensembles of the RCM simulations, introducing the uncertainty in the driving fields and, hence, the uncertainty in the RCM results. Second, they used increased horizontal resolution, ranging from $80 \mathrm{~km}$ up to $20 \mathrm{~km}$, and third, they were based on models with a more sophisticated representation of the land-surface processes.

All these preliminary efforts were focused mainly on evaluating the capability of RCMs in improving the description of climatic features compared with the driving GCMs.
In fact, in each of these studies, one of the main messages was that the RCM was able to improve the driving GCM behavior in reproducing the observed climate anomalies and, consequently, they highlighted that the use of RCMs nested into GCMs was a useful tool for climate prediction purposes.

After these preliminary results, several studies devoted to assess the sensitivity of RCM simulations to model configuration came out. Examples of these studies can be found in Misra et al. [16] who evaluated the impact of two landsurface schemes on the quality of several 6-months long RCM integrations using the regional spectral model (RSM), relying on the relevance of land-surface processes on the predictability of precipitation on seasonal and interannual timescales. However, they did not find a clear improvement on the RCM behavior when using a more sophisticated land-surface scheme. The memory of the soil conditions and the limited length of the integrations may explain the lack of a clear response in the model results. Seth and Rojas [17] and Rojas and Seth [18] performed seasonal-scale simulations using the RegCM model nested into both reanalysis and a GCM. They discussed the sensitivity of seasonal simulations to domain size, horizontal resolution, changes in surface forcing (local land use over the Amazon and soil moisture), and the quality of the driving GCM. The focus of these studies was mainly on the tropical South American region, and the model domain covered the tropics and extended to the subtropical areas. The main findings of these studies were that the sensitivity to the local forcing was larger when a larger domain was considered due to the relevance of the impact of the local forcing on the large-scale circulation. Hence, they concluded that the RCM domain should be carefully configured in order to capture the relevant large-scale circulation affecting the regional climate. Another key finding was associated with the quality on the driving fields, which seriously affects the quality of the RCM simulation. They also quantified the internal variability in the RCM simulation and pointed out the relevance of building ensembles to better understand the response of the regional climate to local forcings. These results represented key findings for further RCM development over the region. Seth et al. [19] explored the capability of the RegCM3 RCM to reproduce daily rainfall statistics on subseasonal timescales over several South American regions and identified a ubiquitous behavior in RCMs related to their tendency to overestimate the frequency of heavy precipitation events. However, their results were limited to only two 5-month integrations, and the number of extreme precipitation events was not large enough to draw robust conclusions. Misra and Kanamitsu [20] explored the anomaly nesting methodology for improving the quality of RCM simulations nested in GCMs, motivated by the fact that GCM biases are inherited through the RCM boundaries and, consequently, transferred into the RCM domain. Though they achieved encouraging results, some inconsistencies in the driving fields due to the methodology produced additional noise in the RCM results. Additionally, their study was restricted to a limited number of seasonal integrations. Rojas [21] explored the extent to which increasing resolution may influence the simulation of precipitation over a region of complex topography. This study was motivated by a systematic rainfall overestimation 
over the upslopes of the Andes, identified in previous RCMs simulations over SA, a common shortcoming shared by other RCM studies over regions with complex terrain elsewhere. In this study, two 5-month long simulations with a triplenested two-way-interacting domains using the MM5 model driven by reanalysis were performed. The model domain was centered over the eastern South Pacific and the western coast of southern SA, with horizontal grid intervals of 135,45 , and $15 \mathrm{~km}$, respectively. The most relevant result of this study was that the horizontal resolution required to reproduce adequate rainfall patterns over the central Andes region is around 30 to $40 \mathrm{~km}$. This range of resolution allows for balancing the compromise between computational capability and quality of the simulations for longer integrations. The capability of simulating the diurnal cycle of rainfall was assessed by da Rocha et al. [22] who performed 17 separated summer season simulations using the RegCM3 RCM nested into reanalysis. Rainfall during summer time over these areas is mostly triggered by convective processes and modulated by other regional forcings, such as sea-breeze circulation and topographic uplift, depending on the region. This study was focused on assessing whether the model was able to capture the timing of the diurnal rainfall cycle which has a contrasting behavior over tropical and subtropical areas. It was found that the model was able to reproduce the main observed features, though some mechanisms associated with the mountain drag and the closure assumptions of the convective scheme were misrepresented and led to large model errors. Evaluating the ability of the model in reproducing these features involves understanding the physical mechanisms that the model can or cannot capture, and, consequently, relevant recommendations for further model improvements were discussed. Sensitivity to model configuration and to the choice of model physics was also explored by Solman and Pessacg [23] who performed several seasonal-scale simulations with the MM5 model to identify the optimum model set up and configuration for climate studies over SA. They explored the sensitivity to the combination of convective and planetary boundary layer schemes and to the treatment of the lateral boundary conditions in simulating a well-known intraseasonal variability pattern of rainfall over SA. They found that the model results were highly sensitive to the choice of the convective scheme and no single combination of model physics was able to outperform them over the entire domain. Moreover, the simulated low-level circulation, which drives the moisture convergence fluxes and, consequently, much of the rainfall anomalies, was also sensitive to the choice of model physics and model configuration. Though several recommendations in terms of model setup were suggested, their results were based on a single season; the skill of $\mathrm{RCMs}$ is regime dependent and consequently no general recommendations could be drawn.

It is worth to recall the study by Fernandez et al. [24] in which a preliminary RCM intercomparison exercise was performed. These authors performed simulations for January for 10 years separately over tropical SA with the RegCM3 and the climate version of the CPTEC Eta model. The aim of this work was to evaluate the capability of the two models in simulating the mean climatological features of the summer circulation over SA. As for several previous studies, the length of the simulations was limited to the monthly scale and the domain covered partially the South American continent. However, the authors identified common shortcomings on the simulations performed with two RCMs, though their results were limited to January conditions only. Moreover, they realized that tuning the regional models was necessary in order to improve their capability in reproducing the mean climatic conditions over several regions of SA.

Taking into account the individual modeling efforts described, most of them focused on the assessment of model performance for mean climatic conditions and interannual variability, mainly for precipitation and temperature, for individual seasons and particular regions. However, not all modeling exercises covered the same domain nor did the simulations cover the same timeperiod; consequently it was not able to look for agreement or disagreement among models' behavior. Moreover, the metrics employed for evaluating model performance were diverse, mainly because each of the studies aimed to evaluate the model capability to reproduce different features of the South American climate.

During the early 2000s regional climate modeling activities over other regions of the world, mostly over North America and Europe, were already examining extended simulations, from one to three decades. The aims of these studies were twofold: first, to evaluate regional climate models' behavior in reproducing present climate conditions nesting the RCMs either into perfect-boundary conditions (reanalysis) or AOGCMs ([9, 25-27] and references therein), second, to assess the regional climate change signal simulated by an RCM nested within time-slice atmospheric AOGCM experiments ([28, 29] and references therein). These studies were mostly devoted to evaluate the added value of long-term integrations with RCMs and to explore the projected changes in mean climate under specified emission scenarios.

These advances in the regional climate modeling community motivated further studies over SA in which the simulated period was enlarged to several decades and continental-scale simulations were performed ([30-36], among others). These studies were mostly focused on evaluating the capability of different RCMs in reproducing different aspects of the South American climate, nesting the models into either reanalysis or GCMs. The regional models mostly used in these studies were the RegCM3, MM5, ETA, and REMO. References about the models can be found in the referred articles. In these studies the RCM simulations covered different periods, were configured over different model domains, and were nested in either reanalyses or GCMs, and a variety of horizontal resolutions were used; consequently, the results could not be directly compared. However, several common issues emerged, such as a dry bias during winter season over southeastern SA and a wet bias over the Andean region and tropical regions. Overall, these studies highlighted the added value of the RCMs in simulating several features of the SA climate and also recognized that model improvements, mostly related to the land-surface processes, were still needed in order to achieve better results.

The first set of RCM simulations devoted to produce highresolution climate change scenarios over the South American 
region was performed by Nuñez et al. [37]. They nested the MM5 RCM into the Hadley Center AGCM (HadAM3) and simulated three 10 -year periods representing present and future climate conditions for the end of the twentyfirst century, respectively, under two emission scenarios: A2 and B2. The domain in their simulations spanned from the subtropics to the southern tip of SA. Garreaud and Falvey [38] evaluated the regional climate change signal over the western coast of the continent from a 30-year simulation using the PRECIS RCM nested into the HADAM3 AGCM. Their domain was centered on central Chile and extended from the subtropics to the southern tip of SA and from the eastern Pacific to central Argentina. Marengo et al. [39, 40] performed several 30-year simulations using the PRECIS RCM and the ETA RCM nested into the HADAM3 AGCM. They focused mainly on evaluating the regional climate change signals over tropical SA and also an exploring the uncertainty in the RCM projections by nesting the RCM into three ensemble members of a GCM. Urrutia and Vuille [41] performed a similar analysis using the PRECIS model nested into the HADAM3 AGCM but focusing on the tropical Andes region. Sörensson et al. [42] assessed the responses of precipitation seasonal means and extremes over SA in a warmer climate using the rossby centre regional atmospheric model (RCA) nested into the ECHAM4 GCM and evaluated the likelihood of occurrence of severe extreme rainfall events and dry spells over the La Plata Basin, northeastern Brazil, and the Amazon basin under the A1B scenario.

All these regional efforts led to the assessment of the regional climate change patterns. Though these regional climate change projections were produced with a variety of RCMs driven mostly by the same AGCM, there was no coordination among the groups performing the simulations. The model domains were different in all the referred studies, and the horizontal grid resolution spanned between 25 and $50 \mathrm{~km}$; however, several common features concerning the regional climate change signal could be identified and an "ensemble of opportunities" could be built. The ensemble of opportunities is not expected to produce quantitative information, but taking into account each individual regional climate change projection, it is possible to evaluate qualitatively the agreement or disagreement of the projected changes among individual modeling exercises. Moreover, common shortcomings could also be identified in terms of the capability of the models in reproducing observed climate features.

Schematically, Figure 2 highlights the areas in which common features arise from the available downscaling exercises considering projected changes for both temperature and precipitation. Most of the models agree on a generalized warming all over the continent, with several hotspots where the temperature increase projected for the end of the twentyfirst century under the A2 scenario is larger than $4^{\circ} \mathrm{C}$ (large red arrows in Figure 2), namely, the Amazon and the Andean regions. Hotspots for the projected precipitation changes show for the summer season a consistent precipitation decrease over the southern Andes and the Amazon region and wetter conditions for central Argentina and the LPB region. For the winter season, the common features are



Temperature change
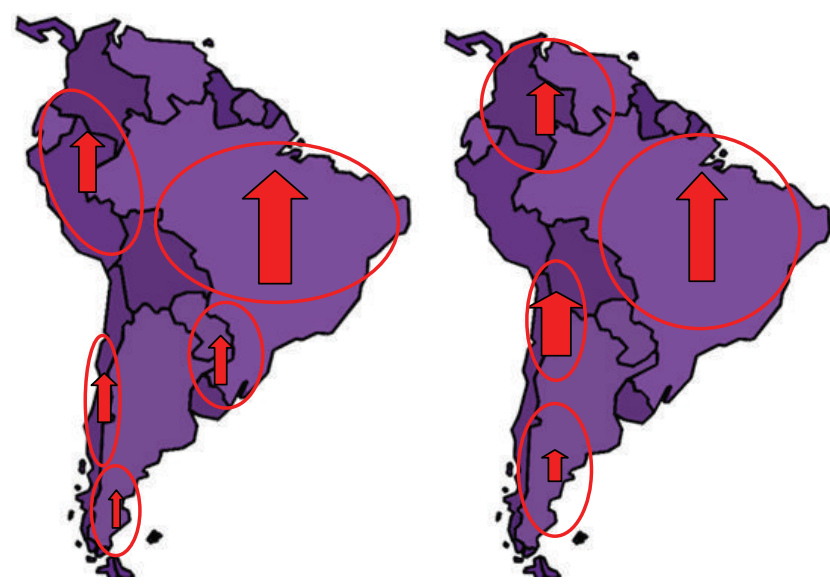

FIGURE 2: Qualitative changes projected at the end of the twentyfirst century under the A2 emission scenario from an "ensemble of opportunities": Precipitation changes (upper panels) and temperature (lower panels). The size of the arrows indicates the magnitude of the projected changes.

wetter conditions over the tropical and southern Andes and drier conditions over subtropical Andes, eastern SA, and the Amazon region.

Though the ensemble of opportunities may provide common results, the regional climate model simulations are sensitive to model configuration and experimental design $[23,43,44]$. Consequently, results from uncoordinated modeling efforts may not provide robust results. It is important to bear in mind that all RCMs included in the ensemble of opportunities were driven by the same AGCM, except the RCA model [42], and it is a well-known fact that the climatic response to a given radiative forcing is model dependent, as shown in several intercomparison exercises using the CMIP3 database [45]. However, Vera et al. [46] explored projected precipitation changes over SA from a subset of CMIP3 AOGCMs and found a general consensus among models on the precipitation changes, particularly an increase of summer precipitation over southeastern SA and 
a reduction of precipitation in all seasons along the southern Andes, suggesting that the limited RCM-based projections were also in agreement with the CMIP3 GCM ensemble.

\section{Coordinated RCM Experiments over South America: Assessing Uncertainty}

Almost all individual modeling efforts described in the previous section were based on results from a single model realization, using either one driving GCM or one RCM, which is insufficient to provide a measure for a comprehensive evaluation of potential climate change and the associated uncertainty. In recent years, several studies have shown that regional climate simulations are affected by several sources of uncertainty ([47] and references therein) and the spread among different climate realizations should be taken into account before drawing conclusions about the significance of the regional climate responses to the external forcings.

The sources of uncertainty in regional climate change projections can be due to (1) the inherent uncertainty of the climate system triggered by differences in the initial conditions, referred to as internal variability; (2) the uncertainty due to models, both RCMs and GCMs, and (3) the scenario uncertainty. Exploring all these sources of uncertainty is a very demanding task, as it requires performing a large amount of RCM simulations with different RCMs nested into different GCMs for different emission scenarios and different realizations with the same model.

In a recent study, Solman and Pessacg [48] explored the relative relevance of different uncertainty sources, namely, internal variability, regional model configuration, and choice of model's physics in seasonal-scale simulations with the aim of characterizing and quantifying the uncertainty in RCM simulations over SA. Their results showed that the internal variability represents the lowest level of uncertainty; the uncertainty due to the choice of model physics arises as the most important source of uncertainty, particularly for temperature and precipitation. They also showed that the spatial pattern of the uncertainty is invariant with respect to the source of uncertainty explored. Though this study was focused on quantifying the level of uncertainty in regional climate simulations, it did not account for the full range of uncertainty sources associated with the regional climate change projections. Moreover, it was based on a 3month simulation, and the dependence of the uncertainty on seasonality could not be discussed. Cuadra and da Rocha [49] evaluated the internal variability using the RegCM3 RCM in order to assess whether the response due to anomalous SST forcing was robust or lies within the intrinsic atmospheric model noise and revealed that quantifying the internal variability is necessary in order to draw robust conclusions on the modeled response of the regional climate to external forcings. The first attempt to explore this issue for regional projections over SA was carried out by [40] who nested the ETA RCM into 4 members of the driving GCM selected to span a representative range of uncertainties. They showed that the spread among RCM realizations was invariant along the annual cycle for precipitation but not for temperature, characterized by a larger uncertainty for the summer months. Moreover, they found that the spread among RCM members was larger for the longer-term projected climate. Though these studies attempted to characterize the uncertainty in RCM simulations, the sources of uncertainty and the length of the simulations were diverse and no common messages could be drawn.

In order to provide useful information for impact studies, the broad range of uncertainties should be considered. This requires the generation of ensembles of simulations performed with different RCMs nested into different GCMs for different emission scenarios in order to explore the full range of uncertainty sources. This approach has been followed by several international efforts, such as the PRUDENCE project [50] and ENSEMBLES project [51] for Europe; the NARCAPP project for North America [52], and CORDEX [4]. These initiatives led to an enormous progress in providing a full quantification of the uncertainty in the projected regional climate, and a huge number of research articles were published elsewhere. For a matter of brevity, we will not refer to them here.

The preliminary collaborative initiative for producing ensembles of RCM simulations over the South American continent was initiated within the EU-FP6 CLARIS project (A Europe-South America network for climate change assessment and impact studies, [53]). Several South American and European institutions participating in this collaborative project agreed on a set of coordinated experiments using different RCMs to produce the first coordinated ensemble for the region. In the first stage, three case studies of 1month long simulations corresponding to anomalous rainfall conditions over southeastern SA were simulated with 6 RCMs. All the models were nested into ERA40 reanalysis. The most outstanding results were published in [54]. This study explored the uncertainty associated with the variety of RCMs and the dependence of the uncertainty on the simulated period. The analysis was focused not only on the uncertainty in simulating the mean climatic conditions but also on simulating extreme rainfall events. Though this was the first study in which coordinated RCM simulations were performed for SA, the simulations spanned over a short period and no robust conclusions could be drawn. In the second stage, a subset of 4 RCMs driven also by ERA40 reanalysis were used to perform multiyear simulations covering the period from 1991 to 2000 . With this set of simulations, Carril et al. [55] evaluated the capability of simulating the major characteristics of seasonal mean climate for SA and the associated uncertainties. They found that the RCMs displayed considerable precipitation biases particularly over tropical and Andean areas. Moreover, the relatively good performance of the multimodel annual precipitation average over La Plata Basin was due to the cancelation of offsetting errors in the individual models. This study also allowed for identifying systematic bias in the simulated climate, such as the tendency of the models to overestimate temperature over southeastern $\mathrm{SA}$, a result that was already present in the previous individual modeling efforts. Moreover, this coordinated modeling effort allowed identifying common shortcomings and strengths of 
RCMs behavior over the region allowing for further model improvements.

A similar initiative was implemented in Brazil by means of the CREAS project (Regional Climate Change Scenarios for South America, [56]). In this framework, three regional models were used: the ETA RCM, the PRECIS RCM and the RegCM3 RCM, all nested in one AGCM (HADAM3). This initiative certainly represented an important step forward in characterizing the uncertainty in regional climate change projections over South America [57, 58]. However, the results were constrained due to the limited number of RCMs used to build the ensemble and because every RCM was forced by a single GCM; consequently, the uncertainty due to the model formulation was certainly limited.

In recent years, the World Climate Research Program (WCRP) has recognized the relevance of providing a conceptual framework for organizing a coordinated international effort to assess and intercompare dynamical and statistical downscaling techniques [4]. This approach was initially coordinated by a Task Force on Regional Climate Downscaling (TFRCD) in 2009 who designed the Coordinated Regional Climate Downscaling Experiment (CORDEX) sponsored by the WCRP. CORDEX was envisaged on the basis of recognizing the relevance of regional downscaling as both an important research topic and an opportunity to engage a broader community of climate scientists in its activities.

The CORDEX initiative has two main purposes: In first place, to provide a framework in which downscaling methodologies can be intercompared through standardized experiment protocols and Second, to provide a coordinated set of downscaled regional climate simulations both dynamical and statistical for the historical past and future periods of CMIP5 GCM simulations for the use in impact and adaptation studies.

The CORDEX protocol includes the definition of common domains covering the majority of land areas around the world and several general issues of RCM configuration, such as resolution, model domain, source of boundary conditions, and simulated periods. In order to encourage the broad scientific community to contribute to this initiative, the standard horizontal resolution for CORDEX simulations was recommended to be around $50 \mathrm{~km}$. More detailed information about the CORDEX framework can be found in [4].

Under the support of the EU-FP7, the CLARIS-LPB project (a Europe-South America network for climate change assessment and impact studies in La Plata Basin; http://www.claris-eu.org/) has been developed in an unprecedented effort providing ensemble projections of climate change over SA and their underlying uncertainties. The modeling strategy was designed following the CORDEX framework so as to contribute to the CORDEX initiative for the South American domain [4].

Every model was configured to cover the South American-CORDEX domain, from $60^{\circ} \mathrm{S}$ to $15^{\circ} \mathrm{N}$ and from $90^{\circ} \mathrm{W}$ to $20^{\circ} \mathrm{W}$, shown in Figure 3. All models were integrated on a horizontal grid of roughly $50 \mathrm{~km}$ (around $0.44^{\circ}$ to $0.48^{\circ}$ ) resolution. For the evaluation framework, a set of 7 RCMs simulations nested into ERA-Interim reanalysis [59] for the period 1990-2008 were performed. The models

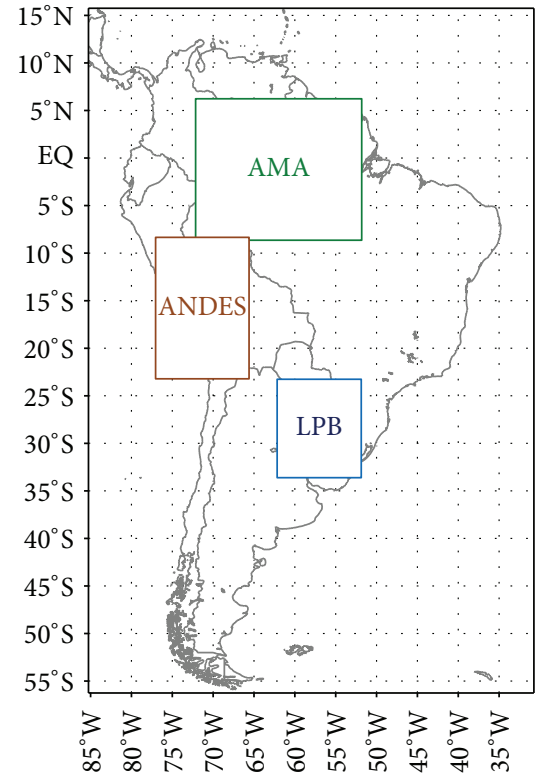

FIGURE 3: CORDEX/CLARIS-LPB model domain. Regions selected for area averages are AMA for Amazon, LPB for La Plata Basin, and ANDES for central Andes region.

participating in this initiative were RegCM3, RCA, MM5, REMO, PROMES, LMDZ, and ETA. A thorough description of each model configuration is described in [60] and references therein.

The analysis of the simulations allowed evaluating the capability of the participating RCMs in reproducing several basic characteristics of the mean observed climate over SA and also characterizing the uncertainty associated with RCMs only. The preliminary evaluation of the RCM ensemble can be found in Solman et al. [60]. This study showed that all RCMs are capaable of capturing the main features of the seasonal mean precipitation and temperature over SA. However, some systematic biases were identified, such as an overestimation of temperature and underestimation of precipitation over the La Plata Basin (LPB) region. Individual model's biases over tropical areas of SA were diverse, depending on the model. The Andean region was characterized by a strong underestimation of temperature and overestimation of precipitation mainly over the Andean slopes, a common shortcoming of every modeling effort for the region. However, it is important to bear in mind that also the quality of observational datasets over areas with complex topography is critical for evaluating model performance, as pointed out by several authors [41, 61]. The lack of high-quality and high-resolution datasets is one of the major shortcomings for evaluating model performance over the South American continent. Though some areas over the eastern part of the continent are well covered by high-quality observations, the tropical area and the Andes are regions characterized by a very sparse data availability. Consequently, it is not possible to provide a robust assessment of model performance, at least over these areas.

The availability of this set of coordinated RCM simulations allowed also exploring the degree of agreement or 




(a)

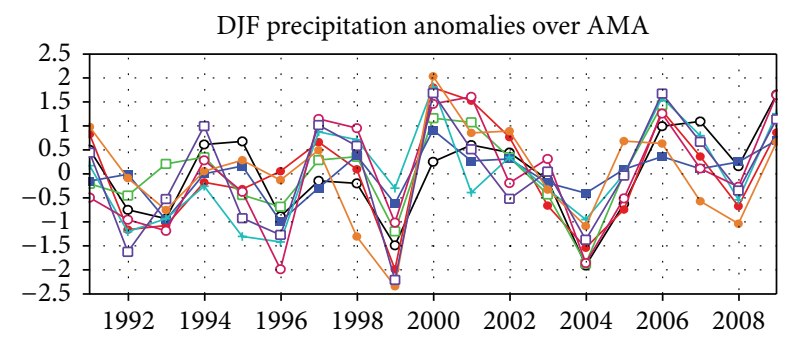

(b)



(c)

FIGURE 4: Time series of seasonal precipitation anomalies from CRU (black line) and the set of RCMs from the CLARIS-LPB/CORDEXcoordinated experiment (colored lines). Top panel is for SeptemberOctober-November (SON) anomalies over LPB. Middle and bottom panels are for December-January-February (DJF) anomalies over AMA and ANDES, respectively. Units of measurement are in millimeter per day.

disagreement among individual RCMs and thus characterizing the uncertainty in simulating regional climate. Overall, it was found that the uncertainty in simulating the main characteristics of climate over the subtropical regions was generally lower compared with tropical regions of the South American continent. Though several systematic biases were identified, the reliability of the simulations is generally good particularly for the LPB region. Moreover, another interesting result raised from this study was that the ensemble of RCMs systematically improves the quality of the simulated climate compared with any individual model, in agreement with similar exercises for other regions of the world.

An assessment of the ERA-Interim driven simulations is summarized in Figure 4, which shows the interannual variability of rainfall as depicted by each individual RCM participating in the CLARIS-LPB/CORDEX evaluation framework for several subregions of South America: the LPB region, the Amazon region, and the Andes region (indicated in Figure 3).
Note that the temporal evolution of seasonal precipitation anomalies for the LPB region from the Climate Research Unit data set is well reproduced by every individual RCM. The RCMs are able to reproduce the interannual variability of rainfall anomalies considering both the timing and the magnitude of the anomalies. Though the RCMs systematically underestimate the rainfall amount [60], they are capaable to capture the year-to-year variability in response to different forcings, such as ENSO. Over the Amazon region, though the models are still able to capture the year-to-year variability of rainfall anomalies, the dispersion among individual models is larger compared with that for the LPB region. Again, the models have a large spread concerning their capability in simulating the total amounts of rainfall and considerably lower skill compared with LPB [60], but they are able capturing its variability. Finally, over the Andes region the RCMs tend to show a weaker agreement with the observations both in terms of the magnitude of the anomalies and in terms of temporal evolution of the seasonal rainfall anomalies. Figure 4 is a good example for the need for both model improvements and highquality datasets to evaluate model performance. The results summarized in this collaborative effort concerning the major strengths and shortcomings of RCMs for SA broadly agree with those from the individual modeling efforts, in terms of the capability of the models in reproducing interannual variability signals and the systematic biases identified. Note also that most of the RCMs participating in this ensemble were already used for the former modeling studies and the models were improved accordingly; however, further model improvements are still pending in order to achieve better model performance.

In the climate change framework, seven RCMs were nested into different GCMs under the SRES A1B emission scenario in order to account for the uncertainty due to both RCMs and GCMs. The matrix of GCM/RCM simulations performed under the CLARIS-LPB project is shown in Table 1, which allowed exploring the most relevant sources of uncertainty in regional climate change projections over SA using a coordinated framework approach.

Taking advantage of the different realizations performed by some of the participating RCMs, a set of 11 simulations were available for both the present climate and the near future climate, and 10 simulations were available for the far future climate.

Figure 5 displays the projected changes for precipitation at the end of the twenty-first century, calculated as percentage differences between the far future (2071-2100) and the control period (1961-1990) under the SRES A1B scenario over the areas highlighted in Figure 3: LPB, AMA, and ANDES for summer (DJF) and winter (JJA), respectively. For LPB the projected precipitation changes seem to be clustered indicating that almost every simulation projects rainfall increase during the austral summer period. The projected precipitation changes for JJA have a larger uncertainty, with a group of models projecting rainfall increase and some models projecting rainfall decrease. Looking at individual RCMs the range in the projected rainfall change goes from $-22 \%$ to $+35 \%$, suggesting a large uncertainty of the projected rainfall changes during winter time. For AMA most of the models 
TABLE 1: Matrix of GCM/RCM combinations of regional climate change simulations over the South America domain performed within the CLARIS-LPB project.

\begin{tabular}{|c|c|c|c|c|c|c|}
\hline RCM/institution & $\begin{array}{l}\text { ERA-Interim } \\
(1990-2008)\end{array}$ & GCM & $\begin{array}{l}\text { Present climate } \\
(1961-1990)\end{array}$ & $\begin{array}{l}\text { Near future } \\
(2011-2040)\end{array}$ & $\begin{array}{c}\text { Far future } \\
(2071-2100)\end{array}$ & $\begin{array}{c}\text { Continuous run } \\
(1961-2100)\end{array}$ \\
\hline \multirow{2}{*}{ RegCM3/USP } & \multirow{2}{*}{$\mathrm{X}$} & HadCM3-Q0 & $\mathrm{X}$ & $\mathrm{X}$ & $\mathrm{X}$ & \\
\hline & & EC5OM-R1 & & & & \\
\hline \multirow{3}{*}{ RCA/SMHI } & \multirow{3}{*}{$\mathrm{X}$} & EC5OM-R1 & & & & $\mathrm{X}$ \\
\hline & & EC5OM-R2 & & & & $\mathrm{X}$ \\
\hline & & EC5OM-R3 & & & & $\mathrm{X}$ \\
\hline MM5/CIMA & $\mathrm{X}$ & HadCM3-Q0 & $\mathrm{X}$ & $\mathrm{X}$ & & \\
\hline REMO/MPI & $\mathrm{X}$ & EC5OM-R3 & $\mathrm{X}$ & $\mathrm{X}$ & $\mathrm{X}$ & \\
\hline PROMES/UCLM & $\mathrm{X}$ & HadCM3-Q0 & & & & $\mathrm{X}$ \\
\hline \multirow{2}{*}{ LMDZ/IPSL } & \multirow{2}{*}{$\mathrm{X}$} & IPSLA1B & & & & $\mathrm{X}$ \\
\hline & & HadCM3-Q0 & & & & $\mathrm{X}$ \\
\hline ETA/INPE & $\mathrm{X}$ & HadCM3-Q0 & $\mathrm{X}$ & $\mathrm{X}$ & $\mathrm{X}$ & \\
\hline
\end{tabular}

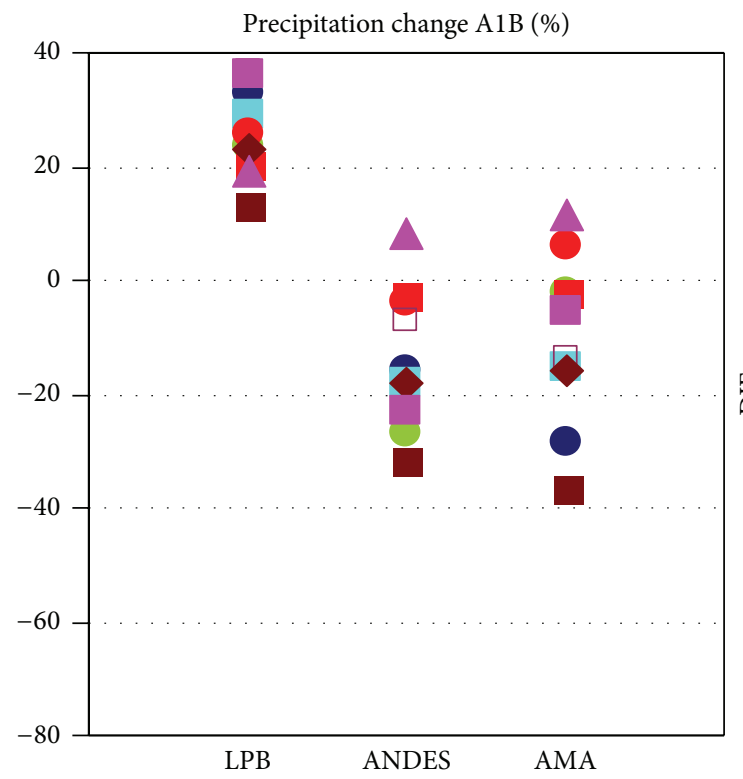

(a)

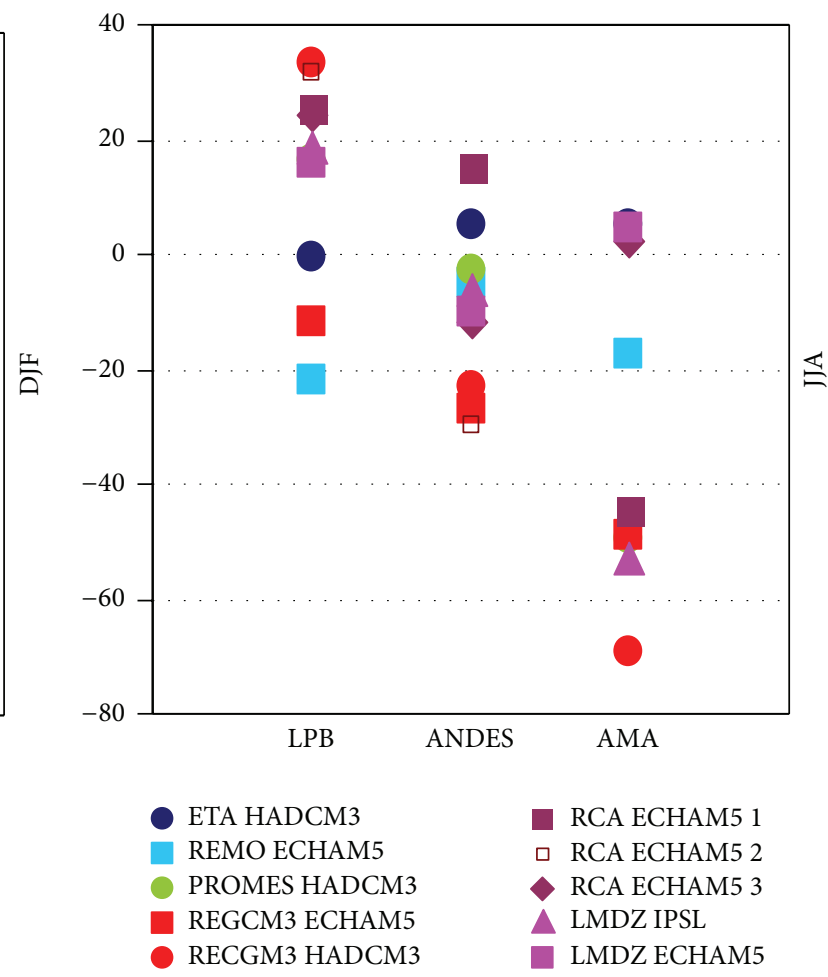

(b)

FIGURE 5: Projected changes of precipitation (as a percentage) between the far future (2071-2100) and the control period (1961-1990) for the SRES A1B scenario for DJF (a) and JJA (b) as depicted by the CLARIS-LPB RCMs, for LPB, ANDES, and AMA regions.

project a decrease of rainfall during both the rainy season (DJF) and the dry season (JJA). Over the ANDES region, the models agree on projecting drier conditions during DJF. For the austral winter season, most of the models agree on a drier future, however, the spread among individual models ranges from $-40 \%$ to $18 \%$.
Inspection of the projected changes showed that though the RCM ensemble gives a good indication of the uncertainty in climate scenarios, it is also important to bear in mind that it does not cover the whole range of uncertainty sources. All simulations were performed under the SRES A1B emission scenario; consequently, the uncertainty associated with the 
TABLE 2: List of the RCM simulations driven by the ERA-Interim reanalysis performed over the CORDEX-South America domain.

\begin{tabular}{l}
\hline RCM/institution-country \\
\hline RegCM3/USP-Brazil \\
RCA3/SMHI-Sweden \\
REMO/MPI-Germany \\
LMDZ/IPSL-France \\
PROMES/UCLM-Spain \\
MM5/CIMA-Argentina \\
ETA/INPE-Brazil \\
COSMO/IACS-Switzerland ${ }^{*}$ \\
WRF/IPSL-France* \\
PRECIS/Met Off-Hadley Centre*
\end{tabular}

${ }^{*}$ Personal communication.

emission scenario has not been explored within the CLARISLPB initiative.

\section{Ongoing RCM Activities and Expected Outcomes}

The CLARIS-LPB contribution to CORDEX-South America has allowed making an unprecedented advance in producing high-quality RCM products for impact assessment studies over the South American continent. Moreover, the coordinated framework allowed also to critically assess the strength and shortcomings of the state-of-the-art RCMs for the region. However, as noted previously, the number of institutions performing the RCM simulations was limited to those participating in the project. Besides, the GCMs selected to drive the RCMs were from the CMIP3 generation and only the SRES A1B emission scenario was selected for the climate change projections.

Under the CORDEX protocol, several institutions using a diversity of RCMs have begun performing RCM simulations for SA for both the evaluation framework and the climate change framework. For the model evaluation framework, beside the CLARIS-LPB project contributions, several other groups have contributed-performing the ERA-Interimdriven simulations. The list of the participating models and groups is detailed in Table 2.

For the climate change framework, CORDEX has recommended producing high-resolution climate change scenarios based on the representative concentration pathways (RCPs). These scenarios are based on prescribed greenhouse gas concentration pathways throughout the twenty-first century, corresponding to different radiative forcing stabilization levels by the year 2100. Four RCPs have been selected, with stabilization levels at $2.6,4.5,8.5$, and $11.2 \mathrm{~W} / \mathrm{m}^{2}$ (referred to as RCP2.6, RCP4.5, RCP8.5, and RCP11.2, resp.), being the highest-priority simulations selected to be the RCP4.5 and RCP8.5, in agreement with the CMIP5 priorities. The simulations cover the historical period from 1950 to 2005 and the future period from 2006 to 2100 . Continuous RCM simulations from 1950 to the end of the twenty-first century are planned to be performed.

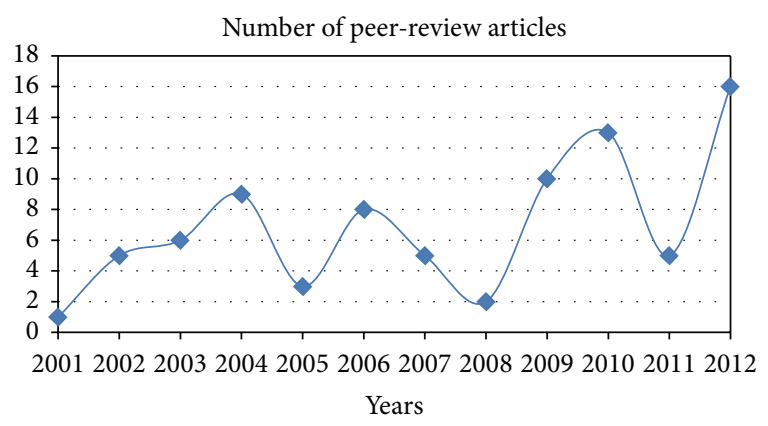

FIGURE 6: Number of peer-review articles published in the literature devoted to regional climate modeling studies over South America from 2000 to 2013. Source: Scopus.

Several groups have already started performing the 150year simulations under several RCPs. The large number of $\mathrm{RCM} / \mathrm{GCM} / \mathrm{RCPs}$ combination will allow exploring the full range of sources of uncertainty affecting regional climate change projections. This will provide valuable climate change information to guide future impact, adaptation, and vulnerability assessments towards defining choices for coping with climate variability and change across SA.

\section{Summary and Conclusions}

In this paper a review of the most outstanding efforts on regional climate modeling over the South American continent has been presented. The regional-scale climate modeling over the region has developed during the last 10 to 12 years, and an enormous progress has been made up to date. An example of this progress can be seen in Figure 6 which shows the number of research articles published on peerreview journals per year. This count has been made taking into account publications based on regional climate modeling studies over SA from the Scopus database.

Early efforts, initiated during the beginning of the 2000s were conducted by isolated initiatives and a reduced number of modeling groups. These early efforts were mostly focused on evaluating the capability of a particular RCM on reproducing some basic aspects of the seasonal climate. From 2002 to 2007, several groups started performing simulations with the different RCMs and focused on evaluating model performance and sensitivity of the RCMs on technical issues, such as model configuration and process studies. Though the modeling efforts were increased, there was still no coordination among the modeling groups. Scince 2008 most of the efforts have been focused on producing regional climate change scenarios. In these studies, the regional climate simulations were extended from 10 to 30 years, and the modeled climatologies were compared with observational datasets, focusing on different features of South American climate. The preliminary studies were based on results from a single RCM.

The CLARIS and CLARIS-LPB projects represented an enormous progress in this regard, due to the coordinated 
framework designed to provide regional climate change scenarios over the South American continent. The coordinated framework allowed to explore the major shortcomings and strengths of the state-of-the-art RCMs over SA and also to characterize the uncertainty in simulating regional climate and regional climate change projections over the region. This unprecedented effort has been the major contribution to CORDEX over the SA region.

It is important to highlight that all the RCMs used to simulate South American climate have been originally developed for other regions of the world, mainly Europe and USA. No single RCM has been developed within South American institutions. Conversely, the RCMs have been evaluated over SA and sensitivity experiments were carried on in order to attain an optimal model setup to get an optimum model performance. However, the general quality of the RCM simulations over the South American continent is not as good as that for Europe and North America. Even when some of the models used are the same as those used for other regions, the biases are larger. Moreover, some of the most recent studies based on ensembles of RCM have identified several systematic biases shared by almost every RCM: the systematic overestimation of temperature over central Argentina during the austral summer months and the underestimation of rainfall over LPB during the austral winter months. Though the reasons for these biases are still unknown, models still need to be improved in order to increase their reliability on simulating South American climate features. One of the key issues is related to the landsurface processes, which have a strong impact on the regional climate behavior, mainly over the tropics and subtropics. Several ongoing research studies are focused on this problem.

Though CORDEX will allow exploring the full range of uncertainty sources characterizing regional climate change projections, there are still some important issues that should be addressed. Almost all the most updated RCM simulations performed or planned for the region are on grids of roughly $50 \mathrm{~km}$ resolution. Though it has been demonstrated that the RCMs have an added value compared with the coarser driving GCMs, the horizontal resolution is still too coarse to capture some regional forcings, and increased resolution may lead to better model performance. Taking into account the messages from the most outstanding studies carried out to date, the major challenges in regional climate modeling over SA are related to model improvement, particularly the improvements on the land-surface schemes, increasing resolution and increasing the ensemble size. These tracks will certainly allow improving the quality of the simulations and fostering the use of RCM outputs for impact and adaptation studies.

Another pending issue is related to the availability of reliable datasets of high-quality observations covering the whole South American continent. Though several gridded databases have been compiled at high-resolution, namely, $0,5^{\circ}$ lat-lon, these are available mostly for precipitation on both daily and monthly bases. To date, the unique highresolution daily dataset for temperature is only available for the LPB region [62]. The need for higher-resolution-gridded datasets of daily precipitation and temperature covering the whole continent remains a challenge for assessing model performance. The availability of high-quality observational datasets is of major relevance particularly for evaluating the models over regions of complex topography, such as the Andes.

\section{Acknowledgments}

This paper has been made under the support of the European Community's Seventh Framework Programme (FP7/20072013) under Grant Agreement N 212492 (CLARIS LPB A Europe-South America Network for climate change assessment and impact studies in La Plata Basin). This work has also been supported by UBACyT Grant X160, UBACyT Grant Y028, and CONICET Grant PIP 112-200801-00195. The author wishes to acknowledge the anonymous reviewers whose comments and suggestions led to improve the original manuscript.

\section{References}

[1] R. J. Stouffer, K. E. Taylor, and G. A. Meehl, "CMIP5 long-term experimental design,” CLIVAR Exchanges, vol. 16, no. 56, pp. 57, 2011.

[2] K. E. Taylor, R. J. Stouffer, and G. A. Meehl, "An overview of CMIP5 and the experiment design," Bulletin of the American Meteorological Society, vol. 93, pp. 485-498, 2012.

[3] F. Giorgi and L. O. Mearns, "Approaches to the simulation of regional climate change: a review," Reviews of Geophysics, vol. 29, no. 2, pp. 191-216, 1991.

[4] F. Giorgi, C. Jones, and G. Asrar, "Addressing climate information needs at the regional level: the CORDEX framework," World Meteorological Organization Buletin, vol. 58, no. 3, pp. 175-183, 2009.

[5] C. Vera, W. Higgins, J. Amador et al., "Toward a unified view of the American monsoon systems," Journal of Climate, vol. 19, no. 20, pp. 4977-5000, 2006.

[6] R. D. Garreaud, M. Vuille, R. Compagnucci, and J. Marengo, "Pesent-day South American climate," Palaeogeography Palaeoclimatology, Palaeoecology, vol. 281, no. 3-4, pp. 180-195, 2009.

[7] J. P. Boulanger, S. Schlindwein, and E. Gentile, "CLARIS LPB WP1: metamorphosis of the CLARIS LPB European project: from a mechanistic to a systemic approach," CLIVAR Exchanges, vol. 16, no. 57, pp. 7-10, 2011.

[8] R. E. Dickinson, R. M. Errico, F. Giorgi, and G. T. Bates, "A regional climate model for the western United States," Climatic Change, vol. 15, no. 3, pp. 383-422, 1989.

[9] F. Giorgi, "On the simulation of regional climate using a limited area model nested in a general circulation model," Journal of Climate, vol. 3, no. 9, pp. 941-963, 1990.

[10] S. C. Chou, A. M. B. Nunes, and I. F. A. Cavalcanti, "Extended range forecasts over South America using regional eta model," Journal of Geophysical Research, vol. 105, no. D8, pp. 147-110, 2000.

[11] C. G. Menéndez, A. C. Saulo, and Z. X. Li, "Simulation of South American wintertime climate with a nesting system," Climate Dynamics, vol. 17, pp. 219-231, 2001.

[12] M. Nicolini, P. Salio, J. J. Katzfey, J. L. McGregor, and A. C. Saulo, "January and July regional climate simulation over South 
America," Journal of Geophysical Research, vol. 107, no. D22, 2002.

[13] P. Nobre, A. D. Moura, and L. Sun, "Dynamical downscaling of seasonal climate prediction over Nordeste Brazil with ECHAM3 and NCEP's regional spectral models at IRI," Bulletin of the American Meteorological Society, vol. 82, no. 12, pp. 2787-2796, 2001.

[14] V. Misra, P. A. Dirmeyer, B. P. Kirtman, H.-M. H. Juang, and M. Kanamitsu, "Regional simulation of interannual variability over South America," Journal of Geophysical Research, vol. 107, no. D20, 2002.

[15] V. Misra, P. A. Dirmeyer, and B. P. Kirtman, "Dynamic downscaling of seasonal simulations over South America," Journal of Climate, vol. 16, no. 1, pp. 103-117, 2003.

[16] V. Misra, P. A. Dirmeyer, and B. P. Kirtman, "A comparative study of two land surface schemes in regional climate integrations over South America," Journal of Geophysical Research, vol. 107, no. D20, pp. 48-9, 2002.

[17] A. Seth and M. Rojas, "Simulation and sensitivity in a nested modeling system for South America-part I: reanalysis boundary forcing," Journal of Climate, vol. 16, pp. 2437-2453, 2003.

[18] M. Rojas and A. Seth, "Simulation and sensitivity in a nested modeling system for South America-part II: GCM boundary forcing," Journal of Climate, vol. 16, pp. 2454-2471, 2003.

[19] A. Seth, M. Rojas, B. Liebmann, and J.-H. Qian, "Daily rainfall analysis for South America from a regional climate model and station observations," Geophysical Research Letters, vol. 31, no. 7, Article ID L07213, 2004.

[20] V. Misra and M. Kanamitsu, "Anomaly nesting: a methodology to downscale seasonal climate simulations from AGCMs," Journal of Climate, vol. 17, no. 17, pp. 3249-3262, 2004.

[21] M. Rojas, "Multiply nested regional climate simulation for southern South America: sensitivity to model resolution," Monthly Weather Review, vol. 134, no. 8, pp. 2208-2223, 2006.

[22] R. P. da Rocha, C. A. Morales, S. V. Cuadra, and T. Ambrizzi, "Precipitation diurnal cycle and summer climatology assessment over South America: an evaluation of Regional Climate Model version 3 simulations," Journal of Geophysical Research, vol. 114, no. D10, Article ID D10108, pp. 1-19, 2009.

[23] S. A. Solman and N. L. Pessacg, "Regional climate simulations over South America: sensitivity to model physics and to the treatment of lateral boundary conditions using the MM5 model," Climate Dynamics, vol. 38, no. 1-2, pp. 281-300, 2012.

[24] J. P. R. Fernandez, S. H. Franchito, and V. B. Rao, "Simulation of the summer circulation over South America by two regional climate models-part I: mean climatology," Theoretical and Applied Climatology, vol. 86, no. 1-4, pp. 247-260, 2006.

[25] F. Giorgi, X. Bi, and J. S. Pal, "Mean, interannual variability and trends in a regional climate change experiment over Europe. I. Present-day climate (1961-1990)," Climate Dynamics, vol. 22, no. 6-7, pp. 733-756, 2004.

[26] L. R. Leung, Y. Qian, and X. Bian, "Hydroclimate of the western United States based on observations and regional climate simulation of 1981-2000-part I: seasonal statistics," Journal of Climate, vol. 16, pp. 1892-1911, 2003.

[27] X. Z. Liang, L. Li, and K. Kunkel, "Regional climate model simulation of US precipitation during 1982-2002-part I: annual cycle," Journal of Climate, vol. 17, pp. 3510-3528, 2004.

[28] F. Giorgi, X. Bi, and J. Pal, "Mean, interannual variability and trends in a regional climate change experiment over Europe. II: climate change scenarios (2071-2100)," Climate Dynamics, vol. 23, no. 7-8, pp. 839-858, 2004.
[29] J. Räisänen, M. Rummukainen, and A. Ullerstig, "Downscaling of greenhouse gas induced climate change in two GCMs with the Rossby Centre regional climate model for Northern Europe," Tellus A, vol. 53, no. 2, pp. 168-191, 2001.

[30] A. Seth, S. A. Rauscher, S. J. Camargo, J.-H. Qian, and J. S. $\mathrm{Pal}$, "RegCM3 regional climatologies for South America using reanalysis and ECHAM global model driving fields," Climate Dynamics, vol. 28, no. 5, pp. 461-480, 2007.

[31] S. A. Rauscher, A. Seth, B. Liebmann, J.-H. Qian, and S. J. Camargo, "Regional climate model-simulated timing and character of seasonal rains in South America," Monthly Weather Review, vol. 135, no. 7, pp. 2642-2657, 2007.

[32] S. A. Solman, M. N. Nuñez, and M. F. Cabré, "Regional climate change experiments over southern South America. I: present climate," Climate Dynamics, vol. 30, no. 5, pp. 533-552, 2008.

[33] M. S. Reboita, R. P. da Rocha, T. Ambrizzi, and S. Sugahara, "South Atlantic Ocean cyclogenesis climatology simulated by regional climate model (RegCM3)," Climate Dynamics, vol. 35, no. 7, pp. 1331-1347, 2010.

[34] M. S. Reboita, R. P. da Rocha, T. Ambrizzi, and E. Caetano, "An assessment of the latent and sensible heat flux on the simulated regional climate over Southwestern South Atlantic Ocean," Climate Dynamics, vol. 34, no. 6, pp. 873-889, 2010.

[35] G. Silvestri, C. Vera, D. Jacob, S. Pfeifer, and C. Teichmann, "A high-resolution 43-year atmospheric hindcast for South America generated with the MPI regional model," Climate Dynamics, vol. 32, no. 5, pp. 693-709, 2009.

[36] J. F. Pesquero, S. C. Chou, C. A. Nobre, and J. A. Marengo, "Climate downscaling over South America for 1961-1970 using the Eta Model," Theoretical and Applied Climatology, vol. 99, no. 1-2, pp. 75-93, 2010.

[37] M. Nuñez, S. A. Solman, and M. F. Cabré, "Regional climate change experiments over southern South America. II: climate change scenarios in the late twenty-first century," Climate Dynamics, vol. 32, no. 7-8, pp. 1081-1095, 2009.

[38] R. D. Garreaud and M. Falvey, "The coastal winds off western subtropical South America in future climate scenarios," International Journal of Climatology, vol. 29, no. 4, pp. 543-554, 2009.

[39] J. A. Marengo, R. Jones, L. M. Alves, and M. C. Valverde, "Future change of temperature and precipitation extremes in south america as derived from the precis regional climate modeling system," International Journal of Climatology, vol. 29, no. 15, pp. 2241-2255, 2009.

[40] J. A. Marengo, S. C. Chou, G. Kay et al., "Development of regional future climate change scenarios in South America using the Eta CPTEC/HadCM3 climate change projections: climatology and regional analyses for the Amazon, São Francisco and the Paraná River basins," Climate Dynamics, vol. 38, no. 910, pp. 1829-1848, 2012.

[41] R. Urrutia and M. Vuille, "Climate change projections for the tropical Andes using a regional climate model: temperature and precipitation simulations for the end of the 21st century," Journal of Geophysical Research, vol. 114, no. D2, Article ID D02108, 2009.

[42] A. A. Sörensson, C. G. Menéndez, R. Ruscica, P. Alexander, P. Samuelsson, and U. Willén, "Projected precipitation changes in South America: a dynamical downscaling within CLARIS," Meteorologische Zeitschrift, vol. 19, no. 4, pp. 347-355, 2010.

[43] R. Laprise, D. Kornic, M. Rapaic et al., "Considerations of domain size and large-scale driving for nested Regional Climate Models: impact on internal variability and skill at 
developing small-scale details," in Climate Change: Inferences from Paleoclimate and Regional Aspects, Proceedings of the Milutin Milankovitch 130th Anniversary Symposium, A. Berger, F. Mesinger, and Dj. Sijacki, Eds., part 4, pp. 181-199, Springer, 2009.

[44] S. A. Rauscher, A. Seth, J.-H. Qian, and S. J. Camargo, "Domain choice in an experimental nested modeling prediction system for South America," Theoretical and Applied Climatology, vol. 86, no. 1-4, pp. 229-246, 2006.

[45] J. H. Christensen, B. Hewitson, A. Busuioc et al., "Regional climate projections," in Climate Change 2007: The Physical Science Basis. Contribution of Working Group I to the Fourth Assessment Report of the Intergovernmental Panel on Climate Change, S. Solomon, D. Qin, M. Manning et al., Eds., pp. 847940, Cambridge University Press, Cambridge, UK, 2007.

[46] C. Vera, G. Silvestri, B. Liebmann, and P. González, "Climate change scenarios for seasonal precipitation in South America from IPCC-AR4 models," Geophysical Research Letters, vol. 33, no. 13, Article ID L13707, 2006.

[47] M. Déqué, D. P. Rowell, D. Lüthi et al., "An intercomparison of regional climate simulations for Europe: assessing uncertainties in model projections," Climatic Change, vol. 81, no. 1, pp. 53-70, 2007.

[48] S. A. Solman and N. L. Pessacg, "Evaluating uncertainties in regional climate simulations over South America at the seasonal scale," Climate Dynamics, vol. 39, no. 1, pp. 59-76, 2012.

[49] S. V. Cuadra and R. P. da Rocha, "Sensitivity of regional climatic simulation over Southeastern South America to SST specification during austral summer," International Journal of Climatology, vol. 27, no. 6, pp. 793-804, 2007.

[50] J. H. Christensen, T. R. Carter, M. Rummukainen, and G. Amanatidis, "Evaluating the performance and utility of regional climate models: the PRUDENCE project," Climatic Change, vol. 81, no. 1, pp. 1-6, 2007.

[51] C. D. Hewitt, "The ENSEMBLES project: providing ensemble based predictions of climate changes and their impacts," EGGS Newsletter, vol. 13, pp. 22-25, 2005.

[52] L. Mearns, W. J. Gutowski, R. Jones et al., "A regional climate change assessment program for North America," EOS Transactions American Geophysical Union, vol. 90, no. 36, pp. 311-312, 2009.

[53] J.-P. Boulanger, G. Brasseur, A. F. Carril et al., "A Europe-South America network for climate change assessment and impact studies," Climatic Change, vol. 98, no. 3, pp. 307-329, 2010.

[54] C. G. Menéndez, M. de Castro, J.-P. Boulanger et al., "Downscaling extreme month-long anomalies in southern South America," Climatic Change, vol. 98, no. 3, pp. 379-403, 2010.

[55] A. Carril, C. Menéndez, A. Remedio et al., "Assessment of a multi-RCM ensemble for South Eastern South America," Climate Dynamics, vol. 39, pp. 2747-2768, 2012.

[56] J. A. Marengo and T. Ambrizzi, "Use of regional climate models in impacts assessments and adaptations studies from continental to regional and local scales: the CREAS (Regional Climate Change Scenarios for South America) initiative in South America," in Proceedings of the 8th International Conference on Southern Hemisphere Meteorology and Oceanography (ICSHMO '06), pp. 291-296, 2006.

[57] J. A. Marengo, T. Ambrizzi, R. P. da Rocha et al., "Future change of climate in South America in the late twenty-first century: intercomparison of scenarios from three regional climate models," Climate Dynamics, vol. 35, no. 6, pp. 1089-1113, 2010.
[58] S. C. Chou, J. A. Marengo, A. A. Lyra et al., "Downscaling of South America present climate driven by 4 -member HadCM3 runs," Climate Dynamics, vol. 38, no. 3-4, pp. 635-653, 2012.

[59] S. Uppala, D. Dee, S. Kobayashi, P. Berrisford, and A. Simmons, "Towards a climate adapt assimilation system: status update of ERAInterim," ECMWF Newsletter, vol. 115, pp. 12-18, 2008.

[60] S. Solman, E. Sanchez, P. Samuelsson et al., "Evaluation of an ensemble of regional climate model simulations over South America driven by the ERA-Interim reanalysis: model performance and uncertainties," Climate Dynamics, 2013.

[61] S. A. Rauscher, E. Coppola, C. Piani, and F. Giorgi, "Resolution effects on regional climate model simulations of seasonal precipitation over Europe," Climate Dynamics, vol. 35, no. 4, pp. 685-711, 2010.

[62] B. Tencer, M. Rusticucci, P. Jones, and D. Lister, "A southeastern south american daily gridded dataset of observed surface minimum and maximum temperature for 1961-2000," Bulletin of the American Meteorological Society, vol. 92, no. 10, pp. 13391346, 2011. 

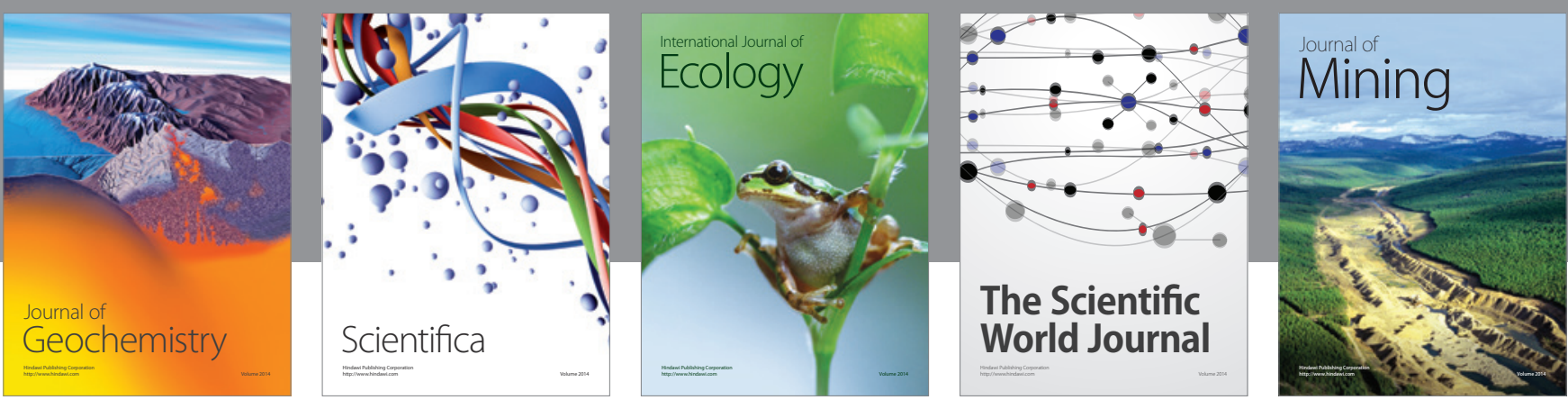

The Scientific World Journal
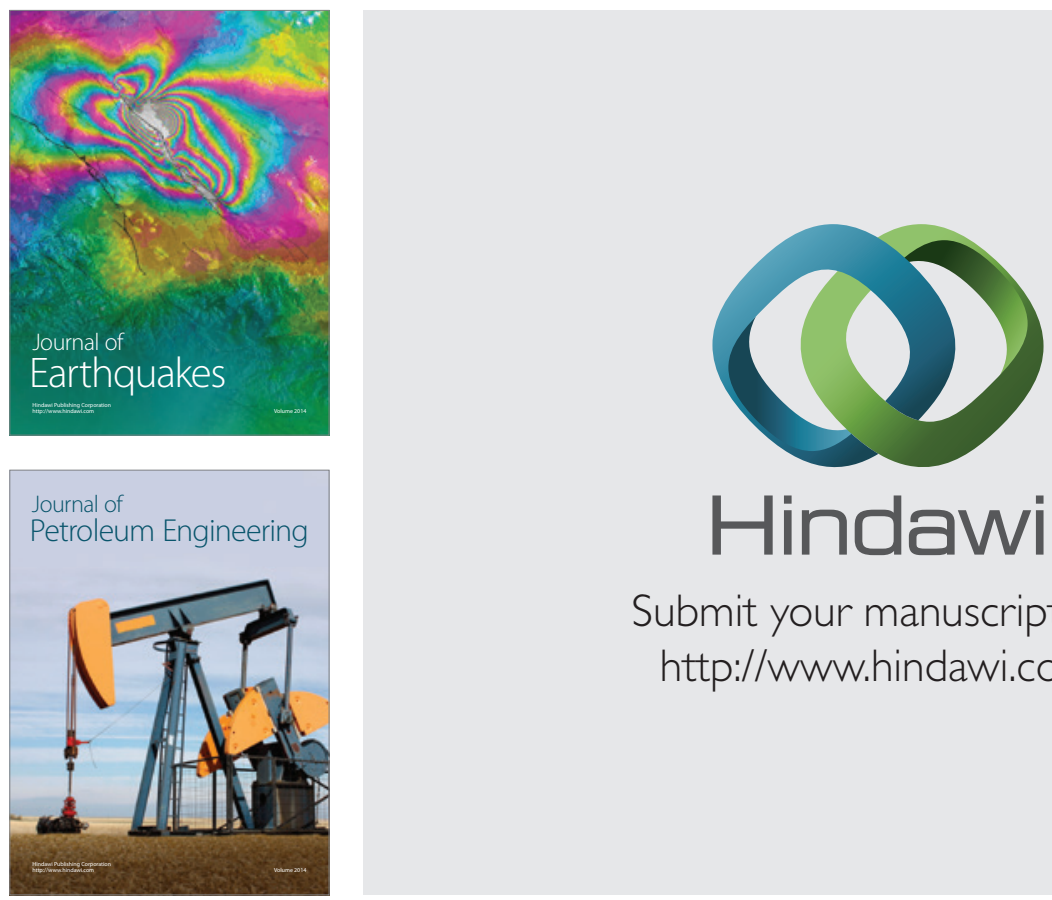

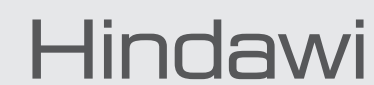

Submit your manuscripts at

http://www.hindawi.com
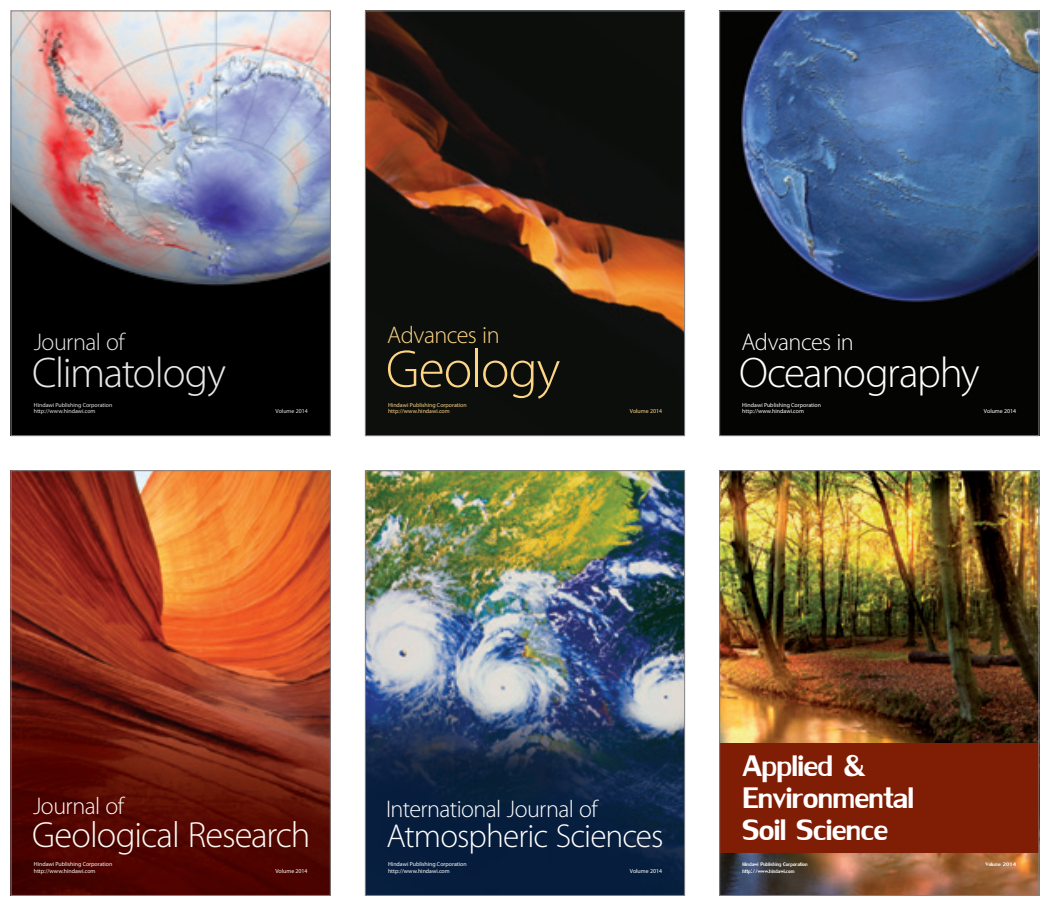
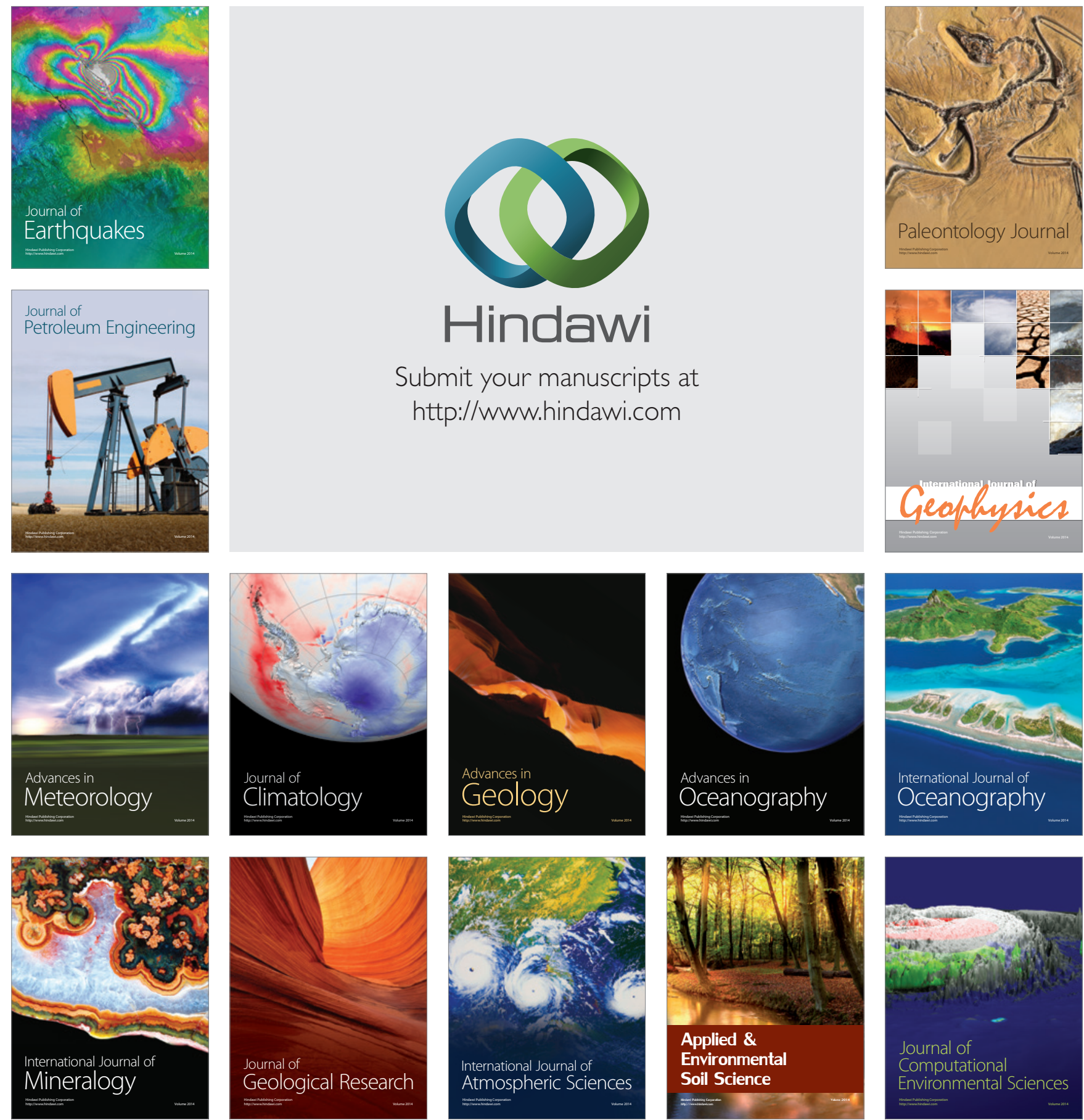